\title{
Future trends in forest pest management
}

\author{
by J. Rod Carrow
}

\author{
Recent Advances in Forest Pest Management \\ Sault Ste. Marie, 21 October 1990
}

\section{Keynote Address}

Canada's forest pest managers have historically worked in a reasonably stable, well-defined environment, with fairly clear objectives - that of protecting trees from unacceptable damage, growth loss and mortality due to pests. In the past decade that environment has evolved into one of uncertainty, and with it the challenge of managing forest pests has become more complex. Of course, we live in a time of uncertainty and change - economic and political restructuring, globalization of trade and technology, atmospheric change all occupy the daily news. But accompanying this is the phenomenon of a paradigm shift, driven by changing human values - an evolution that has seen our quest for a high standard of living being replaced by a quest for quality of living. A shift that will greatly affect the ways in which we develop and manage our forests.

I would like to review the implications of these changes as we approach the year $2000-$ a period that will be characterized by a steadily diminishing industrial wood supply, intensifying management of our new forests, and growing public opposition to many traditional forestry practices, including the use of chemicals. I hope to make it clear that, in the future, resource managers and forest scientists will have to be more adaptive, resourceful, and skilful than ever before.

Four factors set the stage for forest pest management in Canada in the near future - the concept of sustainable development, the National Forest Sector Strategy, the Pesticide Registration Review, and provincial timber supply planning.

\section{Sustainable Development}

Our Common Future (World Commission on Environment and Development 1987) is truly one of the seminal books of this century. It has articulated the fundamental importance of biological sustainability to continuing economic development. It has heightened our awareness of the necessity to integrate environmental protection into economic planning. It has also highlighted the importance of protecting biodiversity as we continue to exhaust our natural resources. As a target for protecting biodioversity, the report proposes that $12 \%$ of the land base be set aside from exploitation. Withdrawals of forest land, such as the Carmanah Valley and Temagami, will continue, and the productive forest land base will progressively shrink. Added to this are aboriginal land claims across Canada. Resolution of these claims has the potential to further reduce the forest land base. This is particularly so in British Columbia, where aboriginal claims encompass $80 \%$ of the forest land.

\section{National Forest Sector Strategy}

The same year Our Common Future was published, Canada tabled its first true National Forest Sector Strategy
(Canadian Council of Forest Ministers 1987) - a document drafted by all major forest stakeholders. The usefulness of the Strategy is that it reflects the judgment and the priorities of those stakeholders. Recommendation \#9 of the Strategy is of particular interest to forest pest managers. Briefly, it recommends:

- the use of pesticides in specific areas, under regulatory control

- the ecological and economic justification of all pest management operations

- more research on the environmental effects of pesticides

- a pesticide registration process that is open and not cost-prohibitive.

\section{Pesticide Registration Review}

In early 1989, the Minister of Agriculture announced a comprehensive review of Canada's pesticide registration system. The review is a consensus-building process, involving all constituencies with an interest in pesticides agriculture, labour, pesticide manufacturers, consumers, environmentalists, public health and alternatives to pesticides. I have the privilege of representing forestry on the Review Team, although after a year and a half of work, classifying this task as a "privilege" is clearly a euphemism. The Team represents Canadian society and its thinking. It is interesting to note that this is a society that, according to a recent survey (Canadian Association of Consumers 1990), is generally unaware of pesticide regulation; only $13 \%$ of Canadians realize that we have government regulation of pesticides. Rather than attempt to revise the current registration system, the Team decided to design a new system, with the central purpose of reducing the risk of using pesticides in Canada. To do so, we identified six guiding principles:

- openness

- protection of health, safety and the environment

- accountability/responsibility/efficiency/fairness

- responsiveness/adaptiveness

- increased access to pest management strategies that may reduce risk of harm to health, safety and the environment

- support for the development of policies that assist economic viability/competitiveness of farming/forestry/ fisheries

All of these principles are supported by the forestry sector. However, with over $70 \%$ of Canadians opposed to the use of chemicals in the forest, the fifth principle takes on special importance, i.e. improved access to lower risk pest management strategies. These strategies will include new control technology that is generally less hazardous. Although the word is deliberately avoided, the focus here will be on "alternatives". Many interest groups across Canada truly believe that "alternatives" to chemical pesticides are readily available to managers and growers right now, and that only the conspiracy of pesticide manufacturers and the archaic 
approach of growers prevent their broadscale adoption. To borrow an expression from another part of our culture, it is time for the alternatives to come out of the closet. Pesticide users from coast to coast repeat the same message: pesticide application is the most disliked job there is, and they would gladly use alternatives if they were available. Let's look for a moment at what has to happen before an alternative is truly available to a pest manager. The term "alternative" generally embraces biorational pesticides, but in the eyes of the public it goes beyond pesticides to cultural and preventive measures for pest management. However, if that alternative is to be used as a control agent, then it must satisfy several criteria:

- it must be federally registered under the Pest Control Products Act

- it must be provincially approved

- it must be reasonably cost-effective

- it must be available in sufficient quantity for operational use.

For forestry use in Canada, it must satisfy a fifth criterion; it must be publicly acceptable. The Canadian public owns almost all the forest land $(92 \%)$ in Canada, and that land base must be managed to reflect the wishes of the owners. Any new control technology must satisfy all five criteria; one or two are not enough to make field use feasible.

It is clear that there are extremely few alternatives to conventional chemical pesticides that satisfy these five criteria. In fact, there are only three: Bacillus thuringiensis kurstaki (Btk), Virtuss, and Lecontvirus, and only one (Btk) is produced commercially. In the recently completed tour of Canada, the Pesticides Review Team heard more than 400 public presentations. I'd like to share with you some of the recurring themes.

(a) country-wide apprehension about the hazards of pesticides to human health and the environment

(b) a belief that the federal registration system should be redesigned to phase out the use of chemical pesticides in Canada by a specified date

(c) a desire to vigorously develop safer pest control technology and promote its field use, accompanied by a similar desire to actively promote more use of integrated pest management (IPM)

(d) an urgent need for new cost-effective control technology in farming, forestry and horticulture, to make them more competitive globally

(e) disagreement about the concept of harmonizing Canadian registration with that of other countries.

Given the lack of awareness of our existing registration system, it's not surprising that the public fails to recognize the essential role of pesticide registration in making new alternative technology available, both in the interest of reducing pesticide risk and promoting IPM. If we do not have a system that defines the testing and evaluation criteria for biochemicals, microbials, and fungal pathogens, etc., they will never be available for operational use. We heard many examples of producers using alternative technology that is not yet approved in Canada, largely because of the failure of the current system to deal with new technologies. It is also clear that the public does not realize that many of the new safer biorational pesticides are in fact, chemicals. The proposed regulatory system (Pesticide Registration Review 1990) is designed to promote pest management, rather than simply make pesticides available. Indeed, the name has been changed to the Federal Pest Management Regulatory System. It is a system with a dual purpose:

(a) to promote the development and use of new control technology and IPM systems that are less hazardous to health and the environment. This function would be handled by the Pest Management Promotion Office

(b) to evaluate and register pest control products. This function would be carried out by the Pest Control Products Management Office.

If the new system is accepted by government, there should be strong incentives for the development and registration of biorational pesticides for forestry, as well as the implementation of IPM systems. Mechanisms under consideration include the administration of a fund for targeted research similar to that of the Ontario Pesticides Advisory Committee, a data base for clients, technology transfer and transitional support for growers.

Historically, forest scientists and managers have tended to remain aloof from the pesticide registration system, perhaps in the belief that understanding the system would somehow be interpreted as promoting the use of pesticides. Whatever the reason, this disinterest must change. Scientists working on new technologies, such as biochemicals, pathogens, and insect biocontrol agents (IBA's), should involve themselves in defining the criteria for health and environmental testing early in the game. Research to satisfy evolving regulatory requirements is more important than ever to the registration and ultimate field use of new technologies.

What are the most promising technologies for forest pest management? Bearing in mind the five criteria I mentioned earlier, but with particular attention to public acceptability, I believe the most promising control agents for insect pests are unaltered, naturally-occurring microbial pathogens; semiochemicals; insect biocontrol agents; hormone analogues and some short residual chemicals such as pyrethroids. The least promising, in my view, are the older generation insecticides (chlorinated hydrocarbons, organophosphates, carbamates) and genetically-altered organisms.

Herbicides deserve special mention. The public generally accepts the need to protect forests from insect and disease damage. However, the need for herbicides to achieve freeto-grow standards and rehabilitate NSR land is not widely understood or accepted. There is scepticism about the concept of growing a tree crop to a pre-determined rotation age, as well as the assumption that regeneration must achieve freeto-grow standards within 5 years of planting, rather than 7 or 10 years. The questions that arise from this assumption are: to what extent are we building a herbicide-dependency into timber management? Are our free-to-grow standards so stringent that herbicides are the only effective technology? To what degree are our timber supply models predicated upon achieving those particular standards? The public challenge of pesticide use in forest management has shifted in recent years to herbicide use; that is clear in the current environmental assessment of timber management in Ontario, where examination of herbicide use has been more penetrating than insecticide or fungicide use. If timber supply modelling across Canada makes the assumption that aerial application of herbicides will be generally used to achieve free-to-grow conditions in regenerating areas, then I think we have seriously misjudged the climate of public opinion. For example, in the Ontario environmental assessment 
hearings, the environmental coalition, "Forests for Tomorrow" has asked that no aerial spraying of herbicides be permitted. There are already several provinces where aerial spraying of herbicides for forestry is not permitted. Furthermore, Ontario has recently elected an NDP government, which through the years, has spoken out against the use of pesticides in forestry. Forest managers need to re-examine the assumptions of timber supply models to ensure that their forecasts are not built on the general availability of aerial spraying of herbicides. At the same time, alternatives to aerial application need to be vigorously pursued by scientists, not to replace aerial spraying, but to give the manager options in the many situations where aerial spraying is not feasible.

\section{Timber Supply Planning}

Timber supply planning, as well as more careful planning of harvesting and protection operations, has become critical to the survival of local mills, both in the short and long terms. As product demand increases, as our inventory of old natural forest declines, and as the productive forest land base continues to shrink, the future becomes less and less certain. Forest pest management plays a vital role in reducing that uncertainty. It is essential for the preservation of the old forest, particularly those stands within the 20-25 year planning horizon. Early in the next century, these old forests will be exhausted in many regions of Canada, and mills will be turning to the new forests for their supply - the forests that Canada has been aggressively establishing since about 1980 . In the past decade, Canada has harvested 7.7 million ha. and planted about 2.2 million ha., at a cost of $\$ 1.7$ billion. We have also tended an additional 1.3 million ha. This investment must be protected, not for a few years, but for the entire rotation - several decades. Failure to provide adequate protection will most certainly jeopardize future investment in silviculture, both through future Forest Resource Development Agreements and Forest Management Agreements. It is important to realize that these obligations will be cumulative in time; looking to the next 5 years, almost every province projects a higher rate of harvesting, planting and tending than in the previous decade.

What type of challenges will the pest manager face in these new forests? Well, they will certainly be different, and they will be tough! With the provinces imposing limits on harvest block size, as well as incorporating elements of landscape design into harvest blocks, aerial spraying technology will have to adapt to smaller, more irregular blocks. The recent trend to register new control products for ground application only presents our sector with a serious problem, since over $90 \%$ of our current pesticide application is by aircraft. Given the high value of our new production forests, as well as the growing number of special purpose stands, e.g. seed orchards, the concept of damage threshold will become more of a reality, as a component of IPM. And of course, the vexing question of how much annual volume increment needs to be preserved to support growth and yield projections will persist.

\section{Future Needs in Forest Pest Management}

With all of this in mind, what are the key factors in forest pest management that deserve our attention in the near future? In my view, there are four:

(a) public justification of pest management operations

(b) protection of our older, natural forests to keep them alive (c) protection of our new forests to maintain vigour and health

(d) development of new control technology and IPM systems. Let me deal with each of these briefly.

\section{(a) Public Justification}

For many years we have operated under the false assumption that because agricultural use of pesticides is accepted, forestry use of pesticides is justified. We have learned through media criticism, civil disobedience, and public opinion surveys that we do not have general public support for the use of pesticides in timber management. The logic of this may not be apparent, but nevertheless, this is the reality we must face. There is an explanation for this apparent contradiction. The great majority of Canadians live in an urban environment, well distanced from their rural heritage. As the quality of that urban environment progressively deteriorates through crowding, contamination of the water and the air, they value more and more what is perceived to be natural. Our forest environment remains as one of of the very few that people think of as being natural; it should come as no surprise that they want it left that way. They are uneasy about anything "unnatural" being introduced into that environment. Whatever the logic, the fact remains that Canadians are opposed to the use of chemical pesticides in forestry.

To address this concern, I am not advocating that we stop using pesticides. But we will have to publicly justify pest management operations, just as we are having to justify harvesting. As the National Strategy states, we should "ensure that all pest management operations are ecologically and economically justified',. How do we translate this into action? I'd like to suggest three attributes that would help greatly to justify pest management operations: purpose, performance standards, and accountability.

A clearly-defined purpose for each operation should be stated. Is it intended to control a pest outbreak? To contain an already existing outbreak and prevent it from spreading? Or is it intended to protect designated trees or stands from unacceptable damage? What is the purpose - outbreak control, containment of an outbreak, or protection?

Having defined the purpose, what is the standard you are trying to achieve? Performance standards are common throughout forestry and in other sectors. There are numerical standards to be met in harvesting, wood utilization, nursery stock production, planting and tending. Yet pest managers, with few exceptions, have been slow to adopt the concept of an operational standard for pest control or protection. Historically, we have tended to report results as being "generally satisfactory", or "variable", or "unsatisfactory", Just peruse the Proceedings of the Annual Forest Pest Control Forums ${ }^{a}$ and you will see what I mean. If you do, you will probably note Rod Carrow as a joint author on many of those reports, so I claim no immunity from this criticism. But times have changed dramatically. We live in a time when everyone is under public scrutiny, and we must provide more rigorous justification for what we do in the forest environment. That is what the environmental assessment of timber management in Ontario is all about - justifying to the public what we do in the forest. Standards must be developed and adopted. Are we trying to achieve $50 \%$ reduction of a pest

\footnotetext{
${ }^{a}$ Annual Forest Pest Control Forums, are organized annually by Forestry Canada, Ottawa
} 
population, or $90 \%$ ? Are we trying to preserve $40 \%$ of the current growth on trees, or $70 \%$ ? I will be the first to admit that our knowledge base for picking these numerical standards is weak, but that is hardly an excuse for failing to use any standard, particularly when the activity involves millions of dollars annually, and attracts so much public criticism. Obviously research is needed to establish credible standards for each of the three purposes I outlined.

The third attribute required for justification is accountability, and on this count, I believe forestry can hold its head fairly high. Through the Pest Control Forum, and provincial reports, the sector does a reasonably good job of openly reporting what pest management operations were carried out on public land. As we have found out through the Pesticides Registration Review, openness and access to information are essential if we are to build public confidence and support for what we are doing. However, as a component of accountability, we will have to improve our assessment of values or benefits that are derived from pest management programs. Attention has focused almost exclusively on risks associated with forestry pesticides, rather than benefits, largely because we have done a poor job of documenting and reporting benefits. Those of you involved in the use of herbicides will understand my point, I'm sure.

\section{(b) Protection of Old Forests}

The second important factor is protection of our older natural forests in order to preserve them for harvesting. The need here is to link our protection programs more closely with harvest scheduling, on a stand basis. Our attention should be focused on the stands included in the long term management plans, as well as the 5-year operating plans. Is the same protection regime required to maintain stands that are scheduled for 15 to 20 years in the future? What level of foliage protection is required? Is annual protection necessary to keep the trees alive, or is biennial treatment adequate? We should also prepare for the possibility that we will encounter new pests, with no registered controls.

\section{(c) Protection of New Forests}

Clearly, protection of our new forests represents a major and difficult challenge. For the first time in our history, we will have to manage pests throughout the entire rotation a period of 40 to 90 years, or longer. Given this time frame, the prospect of climate change takes on more significance. We will certainly encounter new diseases and insects, and the control technology is unlikely to be there when it is needed. However, these are the stands where IPM should become a reality. Because of improved access, smaller stand size, and younger trees, pest detection and monitoring programs become feasible. With our improving capability in growth and yield prediction, the concept of damage thresholds also becomes more useful. This is the environment in which new technologies such as mating disruption, inundative release of IBA's, pheromone trapping and viral control become practical and cost-effective.

\section{(d) New Control Technology}

I come now to the last, and most intractable factor, that of developing new pest control technology. Several years ago, I chaired a Canadian Council of Resource and
Environment Ministers Task Force on forestry pesticides, and in our final report (Carrow 1985), we concluded that the entire process of developing, registering and using pesticides in forest management acted as a major obstacle to the development of new technology. Nothing has changed significantly in the meantime, and indeed, in some respects, the situation is worse. First, let me put Canadian forestry pesticide use in perspective. Pesticide sales in Canada, for all uses, represent about $3 \%$ of the world market; the United States sales represents about $25 \%$. Less than $5 \%$ of the pesticides used in Canada are used in forestry, yet as a major pesticide manufacturer told me recently "you guys attract 90\% of the bad press". To use the Free Trade jargon, this low demand had translated into a very uneven playing field. In the U.S., there are over 130 active ingredients registered for forestry use; in Canada, there are 27 (Canadian Pulp and Paper Association 1987, 1990). Besides low demand, there are some other factors that contribute to this disparity. Provincial bans on the use of pesticides, such as the generic ban of the use of chemical insecticides in Ontario, or the product-specific bans such as 2,4,5-T of a few years ago, create an extremely uncertain environment for $\mathrm{R}$ and $\mathrm{D}$, and for investment. Because these provincial actions are not science-based, and are highly political, they are unpredictable. This unpredictability is a strong deterrent to research and investment, and frankly, it further complicates and obstructs a federal registration system which is already seriously over-taxed. In many cases, provincial actions have seriously undermined public confidence in the federal registration system, a system which in my view has served Canadians well in protecting our health and environment, particularly in the past 25 years. These provincial actions have been taken in response to the use of chemical pesticides, but in most cases, they are so non-rational and unpredictable that they are acting as a major deterrent to the development of new pest control technologies of all types. These technologies are the "safer alternatives" of the future - the same technologies that the provincial agencies want to use. Yet provincial actions are effectively discouraging development. In fairness to provincial staff, I want to point out that most of these actions are political, and do not reflect the judgment of managers.

I would like to leave with you a concept that has recently been presented to Canada's Deputy Ministers of Forestry. Given the low forestry demand for pest control technology, the increasingly stringent and costly federal regulatory system, and the general public opposition to forestry use of pesticides, it is unrealistic to expect the pesticide industry to develop and register new active ingredients for forestry use in Canada, or perhaps to even seek a forestry label for a registered product. As older materials drop out of the market, this could leave Canadian forest managers with less technology for the management of forest pests than we now have. An option is the establishment of a provincial-federal-forest industry consortium to fund the research and development necessary to bring new technology forward for registration. Once the material is registered, its production could be undertaken by the consortium, or alternatively, licensed out to a manufacturer. Many of you will recall a similar federal-provincial cooperative agreement to purchase Canada's fleet of CL-215 water bombers for fire suppression. 


\section{Summary}

In conclusion, I'd like to leave you with just one message. Recommendation \#9 of the National Forest Sector Strategy is highly relevant to the future of forest pest management in Canada. Although the turn of phrase in the recommendation leaves something to be desired, the words are carefully chosen and serve as an excellent guide. In the coming years, we should try to make this recommendation a reality across Canada:

- we should actively incorporate IPM into the management of our new forests, from the time of establishment

- the rationale for existing free-to-grow standards should be critically examined, and the degree of dependency on aerial application of herbicides should be established

- the entire forestry sector should work aggressively to develop and register new control technology that is costeffective and more publicly acceptable, so that products that are considered to be generally hazardous can be replaced over time

- the value of pest management operations, both economic and social, must be documented

- the sector should continue to provide leadership in regulating how it uses pesticides in the forest environment. Applicator training and certification should be mandatory across the country, for both ground and aerial applicators.

What I have left with you is a challenge, but not an unreasonable one. I know that, collectively, the forestry community has the skills and knowledge to succeed in this challenge. However, success does not necessarily follow from skill and knowledge. In today's world, one must also be resourceful, and highly adaptive. Those are the attributes that are sometimes more elusive, but I am confident that we will succeed.

\section{References}

Canadian Association of Consumers. 1990. Food safety in Canada: a survey of consumer attitudes and opinions. Consumers Association Canada, May, 1990.

Canadian Pulp and Paper Association. 1987. Insecticides registered for forest and woodlands management. Can. Pulp and Paper Assoc. Tech. Ref.

Canadian Pulp and Paper Association. 1990. Herbicides registered for forest and woodlands management. Can. Pulp and Paper Assoc. Tech. Ref.

Canadian Council of Forest Ministers. 1987. A national forest sector strategy for Canada. Can. Counc. Forest Ministers, Ottawa.

Carrow, J.R. 1985. Improving the process. Proc. Public Affairs \& Forest Management Pesticides in Forestry Seminar, Can. Pulp and Paper Assoc., Toronto.

Forestry Canada. 1989. 1989 national survey of Canadian public opinion on forestry issues. Forestry Canada, Ottawa.

Pesticide Registration Review. 1990. A proposal for a revised federal pest management regulatory system. Pesticide Registration Review, Ottawa.

World Commission on Environment and Development. 1987. Our common future. World Commiss. Environ. \& Develop. Oxford Univ. Press, New York. 